Pesquisa em Educação Básica 


\title{
Formação continuada de professores para desenvolver uma estratégia de monitoria na área de ciências no ensino fundamental
}

\author{
Patricia da Silva Cavalheiro* \\ Clovis Milton Duval Wanmacher ${ }^{* *}$ \\ José Claudio Del Pino ${ }^{* * *}$
}

\begin{abstract}
Resumo: Esta pesquisa reflexiva apresenta uma integração com assessoramento online-projeto-pesquisa na formação continuada de professores para desenvolvimento de uma estratégia de monitoria em ciências nas séries iniciais. Defende-se o foco na formação de professores por meio do curso de como executar o projeto, tanto das atividades realizadas, como das visitações e dos assessoramentos online. A partir de dados empíricos como transcrições de vídeos, fotografias e questionários, percebe-se que os professores sentem a importância e a necessidade de um agente mediador que os auxilie na busca de soluções à prática docente. Nessa atividade de reflexão conjunta com o professor, estabelece-se um trabalho de cooperação na construção de recursos à estratégia de monitoria.
\end{abstract}

* Doutoranda e Mestre em Educação em Ciências: Química da Vida e Saúde - Universidade Federal do Rio Grande do Sul (UFRGS). Bolsista do programa de Assistência ao Ensino: REUNI. E-mail: patriciaenicole@yahoo.com.br.

* Doutoranda e Mestre em Educação em Ciências: Química da Vida e Saúde - Universidade Federal do Rio Grande do Sul (UFRGS). Bolsista do programa de Assistência ao Ensino: REUNI. E-mail: 00001052@ufrgs.br.

*** Pós-doutorado em Ensino de Química. Professor de Química - Universidade Federal do Rio Grande do Sul, Porto Alegre, RS. Orientador do Programa de Pós-Graduação em Educação em Ciências: Química da Vida e Saúde - Universidade Federal do Rio Grande do Sul (UFRGS). E-mail: delpinojc@yahoo.com.br. 
Palavras-chave: Formação de professores; Estratégia de monitoria em ciências; Assessoramento online.

Abstract: This reflexive research presents an integration with online advisory-project-research in the continuous formation of teachers for the development of a strategy for monitoring science during the early school years. It advocates the focus on the formation of teachers through a course on how to execute the project, both for the activities carried out and the visits and online advising. From empirical data such as video transcriptions, photos and questionnaires, it can be noticed that the teachers feel how important and necessary is a mediating agent who will assist them in pursuit of solutions for the teaching practice. During this joint reflection activity with the teacher a cooperation work is established for the construction of resources for the monitoring strategy.

Keywords: Teacher formation; Monitoring strategy in science; Online consultancy.

\section{Introdução}

Quando fala-se em formação de professores, existem algumas preocupações como: o professor se sente preparado para assumir o papel de educador e pesquisador? O que o professor espera de uma formação continuada? Após longas conversas com professores, percebe-se que, na maioria das vezes, eles gostariam de ter uma formação contínua em que poderiam tirar dúvidas pessoais e não apenas expor suas dúvidas em um blog ou em uma reunião pedagógica, mas ter um contato pessoal, um assessor, 
alguém que poderia auxiliar em um experimento, em um conceito ou apenas perguntar se está tudo bem e se precisaria de algo. Com base na estratégia de monitoria em ciências no ensino fundamental, foi apresentada uma proposta de formação continuada que tem como sujeitos o professor assessor, a supervisora da unidade escolar, o aluno monitor e o professor de ciências, o qual coordena e tem a tarefa de refletir sobre a proposta através dos questionários avaliativos relacionados ao projeto de monitoria em sua escola. Conforme destacado por Maldaner (2003), o professor que reflete sobre sua prática vê sua realidade além do conhecimento da ação e responde aos problemas do dia a dia, de forma a estabelecer uma relação entre o conhecimento e a cultura, recriando suas estratégias. Dewey (1959, p. 30) denomina o pensamento reflexivo como a melhor maneira de pensar e o define como sendo "[...] a espécie de pensamento que consiste em examinar mentalmente o assunto e dar-lhe consideração séria e consecutiva".

O papel do professor assessor torna-se um trabalho reflexivo neste processo. Segundo Alarcão (1996), o professor é aquele que pensa no que faz, que é comprometido com a profissão e que se sente autônomo, capaz de tomar decisóes e de ter opiniões. Ele é, sobretudo, uma pessoa que atende aos contextos em que trabalha, interpreta-os e os adapta à própria atuação. Os contextos educacionais do projeto de monitoria são complexos e nenhum é igual ao outro. Mesmo sendo o projeto aplicado em uma Instituição com os mesmos princípios, cada escola, e até mesmo cada turma, utilizará experimentos práticos diferentes, de acordo com o grupo de monitores e de acordo com o professor coordenador. Portanto, o assessor precisa ter capacidade de analisar e orientar a estratégia conforme as necessidades de cada unidade escolar.

Com o projeto, existe a necessidade de reflexão dos saberes que os professores adquiriram em relação à sua formação, e das pesquisas que desenvolveram para a estratégia de monitoria. Segundo Tardif (2002), embora os professores utilizem saberes diferentes, o uso desses saberes se dá a partir das situações 
vivenciadas. O saber está a serviço do trabalho, significando que os saberes nunca são relações estritamente cognitivas, mas são relações mediadas pelo trabalho, o qual thes fornece princípios para enfrentar e solucionar situaçôes-problema. Pretende-se, com essa estratégia, fazer com que o professor coordenador do projeto, em sua unidade escolar, desenvolva a necessidade da pesquisa, visto que na maioria das vezes se utiliza unicamente das competências técnica e pedagógica para transmitir saberes elaborados por outros grupos de pesquisa.

É importante que esse professor desenvolva um saber prático, baseado em sua experiência cotidiana com os alunos monitores, entre outros critérios, como os que são apresentados para formação do educador, consoante no disposto da lei de Diretrizes e Bases da Educação no ${ }^{\circ}$ 9.394/96:

Art. 61. A formação de profissionais da educação, de modo a atender aos objetivos dos diferentes níveis e modalidades de ensino e às características de cada fase do desenvolvimento do educando, terá como fundamentos: a associação entre teorias e prática, inclusive mediante a capacitação em serviço; e o aproveitamento da formação e experiências anteriores em instituições de ensino e outras atividades.

Tomando por base o artigo de lei, a questão da formação docente não requer apenas a conclusão de um curso superior, exigindo, portanto, a busca por oportunidades de aperfeiçoamento, envolvimento com grupos diversos e assessoramento. Verifica-se aí a necessidade de um prolongamento da formação inicial, o que favorece o aprimoramento teórico-prático da classe, em seu contexto de trabalho e em termos de visão de mundo, dentro de uma cultura geral que alcançará o seu desempenho profissional. A partir da necessidade de formação contínua com pesquisa, da qual nos fala Bruner (1997), de uma revolução inspirada no significado e na construção dos conceitos de uma psicologia humana, entendemos ser necessário pensar em especificidades dos diferentes seres humanos e em suas distintas funções, por isso a escolha de sujeitos com funções diferentes dentro do contexto 
escolar. Dessa forma, passa a ter significado uma análise do interagir na estratégia aplicada e do trabalho da supervisão, além do atendimento de assessoria.

Para melhor esclarecimento, foi entregue a cada unidade escolar as atribuições dos sujeitos desta fase da investigação:

Tabela 1: Função dos sujeitos no projeto de monitoria em ciências

\section{Professor assessor}

Construção do portfólio com experimentos para serem usados nas aulas de ciências com os alunos monitores;

Assessoramento dos professores envolvidos no projeto através de e-mail, de visitação às unidades escolares e de observação, quando necessário e quando solicitado;

Planejar o cronograma das atividades de monitoria com a intervenção do professor de ciências da unidade escolar, a fim de caracterizar as concepções conceituais, em relação ao conteúdo determinado dos alunos monitores e dos alunos das séries iniciais;

Análise de vídeos e de fotos para acompanhar as possíveis modificações na estrutura do projeto;

Análise conceitual de resumos e de esquemas das reuniões;

Análise conceitual de relatórios dos alunos das séries iniciais e de relatórios gerais das professoras regentes;

Análise de resumos e artigos produzidos pelos alunos monitores e auxílio em inscrições nos eventos de iniciação científica, como o UFRGS Jovem.

Supervisão escolar

Auxiliar o professor de ciências no projeto de monitoria;

Orientar, em relação aos bilhetes de autorização, para participação dos alunos monitores no projeto;

Providenciar, junto à escola, o material necessário para as atividades experimentais;

Solicitar, com antecedência, à professora regente, que escolha a atividade que será desenvolvida no portfólio de apoio e entrar em contato com o professor de ciências; 
Solicitar à professora regente relatórios dos alunos e relatório geral de aprendizagem das atividades experimentais monitoradas;

Professor coordenador

Escolher o grupo de monitores com alunos de $6^{\circ}$ e $7^{\circ}$ anos, ou, em casos específicos, $1^{\circ}$ ano do ensino médio;

Fazer, pelo menos, duas aulas experimentais e uma reunião mensal;

Entregar aos alunos a atividade a ser desenvolvida e os materiais necessários;

Acompanhar as aulas experimentais até que o grupo se sinta seguro; Enviar um relatório geral mensal do andamento das atividades à assessora do projeto, via supervisão, para análise;

Incentivar a atuação dos alunos monitores, por meio de atividades orientadas, com o intuito de promover vivência e reflexão sobre estratégias metodológicas de caráter investigativo para o ensino de ciências, tais como exposições teóricas, leituras, discussões em pequeno e grande grupo e resolução de guias de reflexão;

Promover a iniciação científica a partir de participações dos alunos monitores em eventos, como o UFRGS Jovem.

Aluno monitor

Ter disponibilidade de horário para reuniões de planejamento e de avaliação;

Participar ativamente das aulas práticas das séries iniciais;

Auxiliar o professor coordenador nas escolhas de atividades e materiais;

Preparar as atividades experimentais e organizar os materiais no laboratório;

Desenvolver as atividades experimentais junto com a professora regente da turma das séries iniciais;

Ter um caderno de bordo com o relato das atividades e com os resumos das preparações das aulas;

Fotografar e filmar as aulas e as reuniões;

Participar de eventos de iniciação científica, como o UFRGS Jovem.

Fonte: Apostila de explicações sobre o projeto de monitoria em ciências da ACSR 


\section{Metodologia}

O presente artigo é parte integrante do projeto de monitoria em ciências nas séries iniciais, realizado na Associação Central Sul-Riograndense de escolas adventistas (ACSR), e insere-se numa abordagem qualitativa, utilizando-se, como fontes de dados, das seguintes técnicas: questionário, respondido pelos professores de ciências e pelas supervisoras, com análise reflexiva das atividades realizadas de monitoria; filmagem de aulas desenvolvidas no projeto; fotografias de atividades de planejamento e de desenvolvimento das mesmas. Foi realizada uma análise textual discursiva que, segundo Moraes e Galiazzi (2011), permite interpretar as narrativas obtidas nos textos, aprofundando os sentidos e os significados relatados pelos sujeitos. No processo de pesquisa, participaram do questionário quatro professores de ciências e oito supervisoras em sete unidades escolares, sendo que um professor atua em três unidades e, em uma das unidades, há duas supervisoras que desenvolveram o projeto no primeiro semestre de 2012. Apresenta-se uma análise das respostas às perguntas do questionário dos sujeitos envolvidos, que configuram o percurso de suas açốes no projeto de monitoria, e uma análise de suas manifestações quanto à experiência vivenciada.

Os dados apresentados neste trabalho são trechos das respostas dos envolvidos e das discussões reproduzidas, a partir das transcrições dos vídeos das atividades filmadas.

Primeiramente, são expostas manifestações dos sujeitos, nas quais foram expressas as diferentes situaçôes vivenciadas no projeto. Posteriormente, faz-se uma reflexão sobre o papel do projeto na formação continuada dos professores. Para preservar a identidade dos sujeitos envolvidos no projeto, foram utilizadas as seguintes abreviações: 
Tabela 2: Abreviações dos sujeitos envolvidos na pesquisa

\begin{tabular}{|l|l|}
\hline Ass. & Professor assessor do projeto \\
\hline Sup. & Supervisora de cada unidade escolar $(1$ e 2$)$ \\
\hline Alu & Aluno monitor $(1,2,3,4,5,6,7$ e 8$)$ \\
\hline Prof. & Professor coordenador do projeto \\
\hline ALV & Unidade escolar de Alvorada \\
\hline NH & Unidade escolar de Novo Hamburgo \\
\hline CAN & Unidade escolar de Canudos \\
\hline CAM & Unidade escolar de Porto Alegre (Marechal Rondon) \\
\hline CH & Unidade escolar de Cachoeirinha \\
\hline EST & Unidade escolar de Esteio \\
\hline CAX & Unidade escolar de Caxias \\
\hline
\end{tabular}

Fonte: Relatório do projeto de monitoria em ciências da ACSR

Num primeiro momento, foi realizada pelo Assessor do projeto (Ass.) uma palestra para os professores de ciências, as professoras regentes e as supervisoras, na qual foi apresentado, em slides, o projeto, de forma teórica, e algumas fotografias de escolas que já utilizam a estratégia. Após essa palestra, houve necessidade de agendamento para visitaçôes.

Em cada unidade escolar, foi realizado o processo de seleção dos monitores, que se deu através de uma ficha de inscrição. Após a inscrição, foi realizada a prova escrita com conhecimentos de ciências e a prova prática com manuseio de material de apoio às atividades de laboratório e às técnicas de segurança. Com a análise dos resultados, passou-se às entrevistas e à organização do grupo, dentro da disponibilidade de horário. Ficou estabelecido o número de monitores, de acordo com as necessidades, e o número de turmas de séries iniciais, conforme a tabela a seguir: 
Tabela 3: Dados do número de turmas e número de monitores em cada unidade

\begin{tabular}{|l|l|l|}
\hline Unidade escolar & $\begin{array}{l}\text { No }^{\text {de turmas }} \\
\text { envolvidas }\end{array}$ & No $^{\text {de monitores }}$ \\
\hline ALV & 13 & 10 \\
\hline NH & 6 & 18 \\
\hline CAN & 10 & 10 \\
\hline CAM & 18 & 15 \\
\hline CH & 10 & 10 \\
\hline EST & 16 & 22 \\
\hline CAX & 10 & 10 \\
\hline
\end{tabular}

Fonte: Relatório do projeto de monitoria em ciências da ACSR

Nas visitações, estavam presentes, em reunião, os alunos monitores, o professor de ciências e as supervisoras. Nessas reuniões, foram entregues ao Ass. o cronograma de atividades e as datas. O material produzido pela coleta de dados e pelas informações passou por criteriosa classificação, visando à qualificação da fonte e do conteúdo, já que são sete unidades escolares envolvidas. Considerando que foram muitas as informaçóes recebidas de cada unidade escolar, foi necessário filtrá-las e avaliar corretamente a importância e a validade das mesmas. Foram utilizados os dados coletados das diversas fontes, analisados separadamente e comparados os resultados, antes de se unificarem as informações. Como somente pelos questionários não é possível analisar o grau de envolvimento dos alunos monitores, a ansiedade das supervisoras e a intensidade do trabalho dos professores, também foram analisados vídeos de reuniões de planejamento. 


\section{Análise de dados}

O professor desempenha um papel ativo no processo de educação. A compreensão que o professor tem do aluno e do que deve realizar com ele tem muitas implicaçôes em seu trabalho. Foi necessário fazer um levantamento do livro didático utilizado na Instituição, bem como de materiais didáticos de outras editoras e de sites da internet, a fim de montar um livro de apoio ao professor com experimentos e atividades para serem realizadas nas séries iniciais com os alunos monitores. Essa tarefa levou tempo e dedicação do Ass. Além desse material, também foi necessário elaborar a palestra e as visitas às unidades escolares. Segundo Vygotsky (2003), é preciso se desdobrar para realizar as diversas funções que competem ao professor em muitas situações que devem ser descobertas e assumidas, conforme o andamento das atividades e do desenvolvimento da unidade escolar. O Ass. é, nesse projeto, o organizador do ambiente social.

Neste contexto de preparação e aplicação do projeto, o papel da supervisora também se faz importante quanto ao bom andamento do mesmo. Em alguns momentos, o que se percebe é uma grande preocupação por parte dela com a questão dos materiais e não com a questão de aprendizagem dos alunos envolvidos, como podemos ler nas respostas aos questionários:

Participei de algumas das práticas no laboratório e verifiquei que o registro ocorre apenas no diário de bordo feito pelo aluno monitor responsável. O professor se reúne em conversas periódicas e o diário de bordo fica na pasta da monitoria com o responsável (aluno do EM). Ainda não peguei a pasta para olhar. Semana passada, conversei com todos os monitores, repassando as principais orientaçốes e checando se tudo foi bem esclarecido. Vejo o projeto em minha escola em crescimento. Precisamos mostrar aos monitores a seriedade da proposta (Sup. NH).

Percebo que falta disponibilidade de tempo para o professor fazer reuniões com os alunos envolvidos no projeto e que o laboratório precisa 
de bancos em melhor estado, pois as bancadas do laboratório são muito altas para os alunos do ensino fundamental (Sup. ALV).

Nessas unidades escolares, as supervisoras demonstram preocupação com a qualidade do laboratório, com materiais e disponibilidade de tempo para o professor auxiliar na produção dos alunos monitores, como percebe-se claramente na fala da Sup. NH.

A Sup. ALV destaca o projeto em sua escola como sendo de grande relevância. Numa das visitas de assessoria, as transcriçôes das filmagens evidenciaram uma supervisora comprometida com o projeto, pois ela havia separado fotografias e também preparado uma apresentação em slides para um encontro de supervisoras em Governador Celso Ramos, no CATRE (Centro de Treinamento das unidades escolares adventistas de Santa Catarina).

Na unidade CAM, as filmagens mostram uma reunião com monitores, supervisoras e professor coordenador. Nessa reunião, o professor expôs seu objetivo de levar os alunos monitores em eventos, como a FEBRACE (Feira Brasileira de Ciências e Tecnologia de São Paulo). As duas supervisoras envolvidas no projeto fotografaram cada momento. Enquanto o professor responsável conversava com os alunos monitores, explicando o projeto, uma supervisora auxiliava no andamento da reunião com colocações de grande importância e completava algumas citações do professor responsável. Uma supervisora fazia o trabalho de apoio às professoras regentes e ao professor responsável na elaboração dos cronogramas e temáticas das aulas, enquanto a outra fazia o trabalho de apoio aos alunos monitores em relação ao caderno de bordo, com as anotaçôes para a atividade e os materiais de apoio. A seguir, alguns trechos dos questionários avaliativos dessas supervisoras:

Os experimentos são selecionados durante o intervalo das aulas do turno da manhã. Nas quintas à tarde, os alunos se reúnem para preparar a aula de laboratório e, na quinta seguinte, eles realizam a experiência com os alunos do fundamental. Os alunos envolvidos no projeto melhoram suas notas em ciências e eles mesmos sugerem experiências para realizar 
na próxima aula com os alunos do fundamental. Eles participam mais das aulas e demonstram um maior interesse nas mesmas. Os alunos são monitorados pelas câmeras instalados no laboratório. É realizada uma reunião mensal com os alunos também na quinta à tarde com a presença do professor (Sup. I CAM).

Os materiais são de fácil aquisição, simples e úteis, de maneira que facilitam a realização da experiência. Os materiais são adquiridos por experiência, desta forma os organizamos e, se precisar comprar algo que não temos no colégio, os alunos compram e trazem a nota para serem reembolsados. A principio, não tivemos nenhum problema com a organização dos materiais (Sup. 2 CAM).

Nesses trechos, percebe-se que o papel das supervisoras nessa unidade é bem definido. Segundo Alarcão (1996), o objetivo é fazer com que os professores sejam capazes de realizar o seu trabalho, acompanhados pela supervisão. Um professor, individualmente, tem influência apenas sobre suas turmas, mas quando pensa no coletivo, com outros educadores, chega a uma metáfora, a da escola reflexiva.

Segundo Tardif (2002), os professores não colocam todos os saberes em igualdade. Os saberes oriundos da experiência sugerem uma avaliação maior. A experiência de trabalho é apenas um espaço no qual o professor aplica seus saberes, uma reflexividade daquilo que se sabe naquilo que se faz, a fim de produzir sua própria prática profissional. Em resposta aos primeiros questionamentos, verifica-se que a reflexão do que pode ser feito está assumindo, aos poucos, o planejamento dos professores envolvidos no projeto, como vemos nestes recortes de respostas aos questionários avaliativos:

As atividades sugeridas são interessantes e melhoram a compreensão dos alunos nas aulas de ciências. O material é bem acessível e, por enquanto, não tivemos dificuldade em obter os materiais sugeridos nos experimentos (Prof. ALV).

Os desafios são muitos: o tempo, o planejamento, as reuniões que devem ocorrer periodicamente, o ajuste dos grupos. Mas na verdade, todas essas coisas se tornam pequenas diante dos resultados do projeto. Esse 
projeto me ajuda, de várias formas, na minha formação continuada, pois pesquiso exemplos e maneiras de melhorar a didática das aulas dos monitores e busco formas e experiências variadas para eles entenderem como ministrar a aula (Prof. CAM).

De acordo com Schön (2000), o olhar sobre as competências e os saberes é necessário para que os professores possam desempenhar bem seu trabalho. Nota-se que o autor defende que a origem da crise no sistema educacional dos últimos anos da década de 1980 vem, entre outros fatores, da desconfiança no conhecimento profissional dos professores, o que por sua vez exige a "[...] busca de uma nova epistemologia da prática". Com o projeto, propõe-se desafios que estão, de certa forma, contribuindo para a formação dos professores envolvidos, como lemos no relato do Prof. $\mathrm{CH}$ :

Vejo dificuldade na adaptação da linguagem à faixa etária. Aprendo sempre, mas nunca acompanhei. As atividades são escolhidas conforme o tema que estamos estudando, são marcadas numa folha que o SOP nos passa e os monitores se reúnem comigo, quinzenalmente, para planejar essas aulas. Os monitores pesquisam bastante, trazem materiais, empenham-se, mas precisam melhorar a postura de apresentação. Os materiais são interessantes. Quem organiza tudo são os monitores (Prof. $\mathrm{CH}$ ).

Gosto da proposta e acredito ser uma ótima oportunidade de crescimento para os alunos monitores e para mim. É um projeto interessante, pois proporciona aprendizado a todos os envolvidos. O principal desafio é estar presente nas práticas, ajudando os monitores a entenderem a seriedade da proposta (Prof. $\mathrm{NH}$ ).

$\mathrm{Na}$ unidade $\mathrm{NH}$, como pode ser observado pelo vídeo enviado pelo professor, o projeto está em andamento, este assumiu com seriedade o projeto. Dessa unidade, temos muitos dados, como cadernos de bordo, pastas com fotografias, resumos e artigos publicados em eventos, como o FEBRACE e o MOSTRATEC (Mostra Internacional de Ciências e Tecnologia que acontece na cidade de Novo Hamburgo), e os alunos monitores são muito interessados. Esse ano, o professor preferiu 
trabalhar com o dobro do número de monitores indicado para essa unidade. Para a supervisora, o projeto tornou-se complexo por trabalhar com tantos monitores, visto que a escola não tem muitas turmas de séries iniciais, mas o professor coordenador disse, em reunião, que queria tentar uma "nova roupagem" do projeto. De acordo com Tardif (2002), é de grande significado que os professores utilizem diferentes saberes, em função das situações em relação ao seu trabalho, pois essas reflexões fornecem princípios para solucionar situações cotidianas.

Segundo Carvalho e Gil-Pérez (1998), os professores de ciências precisam saber fazer uma proposta baseada na pesquisa. É preciso auxiliar o professor com uma formação continuada que permita uma construção de programas de atividades. Com o projeto de monitoria em ciências, esta atividade torna-se visível. Nesta o professor vai muito além do ato de ministrar aula: ele age como orientador das equipes de "pesquisadores iniciantes", criando um ambiente de trabalho adequado e transmitindo aos alunos monitores seu próprio interesse pela tarefa e pelo progresso de cada aluno. E possível verificar esse processo em uma das respostas de uma professora a seguir:

O projeto faz com que os alunos se dediquem mais aos estudos e gostem mais da disciplina de ciências, melhorando o aprendizado dos educandos. Seria importante uma maior disponibilidade de tempo para o professor fazer reunióes com os alunos envolvidos no projeto. As metas são fazer os alunos gostarem de ciências, conhecerem o laboratório e aprenderem a cuidar dos materiais, dos reagentes e da vidraria do laboratório. A prática experimental propicia ao aluno compreender melhor alguns conteúdos da área de Ciências Naturais. Por meio dela é possível vivenciar o processo de investigação científica, compreender conceitos básicos, manipular materiais, seres vivos, objetos e instrumentos, desenvolver a capacidade de resolver problemas e desenvolver o espírito investigativo, pois os alunos envolvidos no projeto melhorando suas notas em ciências, eles mesmos sugerem experiências para realizar na próxima aula com os alunos do fundamental. Eles participam mais das aulas e demonstram um maior interesse com as mesmas (Prof. CAX).

Segundo Schön (2000), a formação é um processo tutorado que se baseia na "reflexão na ação". O ato de pensar no que se faz 
e de fazer pensando em cada ação faz o processo de aprendizagem ser um constante crescimento, tanto para o aluno monitor como para o professor coordenador do projeto na sua unidade escolar. Na unidade ALV, em reunião, percebe-se essa interação aprendizagens-habilidades:

"Com esse projeto, quero aprender a ter mais paciência. Falo pouco. Quero aprender a me organizar melhor e ser mais criativa.” (Alul)

"Espero aprender coisas novas e espero que o projeto ajude no meu futuro.” (Alu 2)

"Quero aprender a viver em sociedade, sou tímido, quero melhorar. Ter mais responsabilidade.” (Alu 3)

"Tenho muito medo de errar, então acho que será um desafio, para mim, entrar nesse projeto.” (Alu 4)

"Uma forma de aprender e pesquisar." (Alu 5)

Mudar o foco para o desenvolvimento de competências e habilidades implica, além da mudança de postura da escola, um trabalho pedagógico integrado em que se definam as responsabilidades de cada um, tanto do aluno como do professor. É necessário que o professor se sinta responsável pela formação global de seu aluno e não por um único aspecto informativo e relacionado à sua área específica de atuação.

$\mathrm{Na}$ Unidade CAX, as transcrições dos vídeos proporcionam um acompanhamento completo das reuniões, nas quais se verificam uma professora que tem sempre em mãos o material de apoio feito pela Ass., que motiva bem os monitores e que registra tudo com bastante atenção às informações. Uma pergunta, de um aluno monitor, que marcou nessa transcrição foi "Como faremos o caderno de bordo com as fotos? Pode ser a mão ou precisa ser digitado? E fotos? Podemos inserir enquanto digitamos?" (Alu 6). Na unidade EST, uma colocação semelhante: "Posso fazer o caderno de bordo no notebook? É mais fácil do que esse negócio 
de escrever.” (Alu 7). É importante discutir essa questão com os professores coordenadores e verificar como está a "escrita" no projeto, o que numa próxima etapa da pesquisa será analisada com mais profundidade.

Uma recente pesquisa realizada na Universidade de Stavang (Noruega) aponta que escrever é melhor que digitar. Segundo eles, a explicação é simples: escrever envolve muito mais sentidos do que digitar e, por isso, facilitaria o aprendizado e a memorização do que é escrito. $\mathrm{O}$ estudo foi feito com dois grupos de crianças: o primeiro escreveu o alfabeto a mão, enquanto $o$ segundo digitou. No final do trabalho, ao perguntarem se eles lembravam o que haviam escrito, o primeiro grupo saiu-se melhor. Conforme os pesquisadores, partes diferentes do cérebro são ativadas quando lemos as letras digitadas e quando reconhecemos as letras escritas a mão. "Ao escrever, os movimentos envolvidos deixam uma memória na parte sensorial e motora do cérebro, que ajuda a reconhecer as letras e cria uma conexão entre leitura e escrita", explica Anne Mangen, professora do Centro de Leitura da Universidade de Stavang.

A Unidade EST enviou muitas fotografias e pequenos trechos de gravaçóes. O projeto está em andamento, o professor participa ativamente com a supervisora na reunião analisada. Percebe-se que, nessa reunião, a supervisora não se expõe muito e o professor tem sempre a palavra final. Os monitores perguntam bastante e, entre as diversas colocaçôes, uma em especial: "Quero ir para o UFRGS Jovem" (Alu 8). O professor disse que sim e ainda acrescentou que poderia pesquisar sobre o evento, dizendo: "Espero que tenham uma boa produção de material, pois temos eventos para participar" (Prof. EST).

O UFRGS Jovem é um espaço multidisciplinar para a divulgação das atividades de iniciação científico-tecnológicas realizadas por alunos e professores da educação básica e profissional. A Pró-Reitoria de Pesquisa (Propesq) amplia a divulgação das atividades de iniciação científico-tecnológicas, oportunizando o aprender pela pesquisa às crianças e aos jovens no âmbito das 
escolas, portanto, numa etapa anterior a de se tornarem alunos universitários.

O Professor da Unidade EST procura se aperfeiçoar, sempre que possível está online, conversando sobre suas estratégias e melhorando suas práticas com o professor assessor, também participa de congressos e seminários. Segundo Alarcão (1996), quem está em contínua formação precisa de alguém que o ajude, levando-o a responder perguntas que, a princípio, ele não é capaz de se fazer. Ao aprofundar o nível das questões, ele aprofunda o próprio conhecimento.

\section{Considerações finais}

É preciso destacar que o modelo online de assessoramento de formação profissional não representa um caso isolado aos docentes. Encontramos essa metodologia em outras áreas profissionais, como no caso de profissionais da área de venda, contabilidade e medicina. Atualmente, veem-se na internet sites de assessoramento aos professores, mas gerando custos para os mesmos e grande quantidade de blogs sobre o assunto, porém um tanto superficiais.

A formação contínua na estratégia de monitoria em ciências com o professor assessor concentra-se nas necessidades e nas situações vividas pelos professores no projeto, assim como nos seus desafios, nas sugestões de aperfeiçoamento, adaptações dos saberes em relação à realidade de cada grupo de monitores e suas pesquisas. Nesse sentido, as relações entre pesquisa e profissão podem contribuir à estratégia de monitoria e fazer dessa estratégia um momento de aperfeiçoamento de um professor integrado e pesquisador.

Segundo Tardif (2002), as fontes da formação profissional dos professores não limitam-se à formação inicial na universidade, trata-se, no verdadeiro sentido do termo, de uma formação contínua que abrange toda a carreira docente. É também nesse 
contexto que a formação continuada encontra o seu espaço nas necessidades pedagógicas, conforme afirma (LIBÂNEO, 2004, p. 227):

[...] a formação continuada pode possibilitar a reflexividade e a mudança nas práticas docentes, ajudando os professores a tomarem consciência das suas dificuldades, compreendendo-as e elaborando formas de enfrentá-las. De fato, não basta saber sobre as dificuldades da profissão, é preciso refletir sobre elas e buscar soluções, de preferência, mediante ações coletivas.

De acordo com Cavalheiro e Del Pino (2010), é necessário visualizar o papel do professor como uma atitude prática, melhorando o ensino, considerando as crescentes demandas nas exigências sociais, como foi visto na fala do Prof. CAM. Nesse contexto, o professor orientador do aluno monitor faz com que a atividade seja um momento em que a organização do trabalho cooperativo alcance novos paradigmas e alteraçôes diversas, reclamando o reencontro de seres pensantes, aptos e atuantes na perspectiva de construir respostas educacionais que atendam a dinâmica social do trabalho docente. Especialmente pelo seu caráter conjunto e pela interação com os alunos monitores, rumo ao alcance dos objetivos do projeto, os quais retratam uma função social na escola e um ensino no qual se vivencie a garantia de uma educação para a vida, ou seja, o que se aprenda na escola seja útil na vida fora de qualquer instituição.

Espera-se, do professor do novo século, atitudes norteadas por dinâmicas, como agir como orientador, deixando de lado a postura de preceptor; orientar e motivar, convidar e não impor a autoridade. O professor não é quem ensina, mas o eterno aprendiz, que aprende melhor e está à frente dos desafios, ou seja, a aprendizagem deve ser permanente (DEMO, 2003).

Essa estratégia de monitoria, na qual a supervisora escolar tem um papel ativo ao lado do professor coordenador, faz com que ocorra uma ruptura com o individualismo pedagógico, ou seja, faz com que o trabalho e a reflexão em equipe se tornem necessários; uma análise da prática, permitindo desenvolver, com 
uma formação de nível elevado, um estatuto profissional, um profissionalismo aberto, isto é, em que o ato de ensinar é precedido de uma pesquisa de informações e de um diálogo entre os parceiros interessados (RODRIGUES; ESTEVES, 1993).

O princípio que orienta este trabalho foi alcançado a partir da formação pela reflexão sobre a estratégia pedagógica de monitoria. Nessa atividade de reflexão conjunta com o professor, estabeleceu-se um trabalho de cooperação na construção de recursos à estratégia de monitoria. No decorrer do processo, percebe-se que os professores sentem a importância e a necessidade de um agente mediador que os auxiliem na busca de soluções inteligentes para o gerenciamento e a qualidade do seu trabalho na escola e que ainda se tenha muito para pesquisar em relação ao desenvolvimento e à aprendizagem dos alunos monitores envolvidos e alunos das séries iniciais, os quais são os sujeitos fundamentais desse processo de interação.

\section{Referências}

ALARCÃO, Isabel. (Org.). Formação reflexiva de professores: estratégias de supervisão. Portugal: Porto Codex, 1996.

BRASIL. Lei de Diretrizes e Bases da Educação Nacional, 1996.

BRUNER, Jerome. Atos de significação. Porto Alegre: Artes Médicas, 1997.

CARVAlHO, Ana Maria Pessoa de; GIL-PÉREZ, Daniel. Formação de professores de ciências: tendências e inovações. 3. ed. São Paulo: Cortez, 1998.

CAVALHEIRO, Patrícia da Silva; DEL PINO, José Claudio. Monitoria como estratégia pedagógica para o ensino de ciências no nível fundamental: uma reflexão ao professor. Porto Alegre: IASD, 2010.

DEMO, Pedro. Educar pela pesquisa. 6. ed. Campinas: Autores Associados, 2003. 
DEWEY, John. Democracia e educação. Tradução de: Godofredo Rangel e Anísio Teixeira. 3. ed. São Paulo: Nacional, 1959. (Trabalho originalmente publicado em 1916).

LIBÂNEO, José Carlos. Organização e gestão da escola: teoria e prática. 5. ed. Goiânia: Alternativa, 2004.

MALDANER, Otávio Aloísio. A formação inicial e continuada de professores de Química. Ijuí: Unijuí, 2003.

MORAES, Roque; GALIAZZI, Maria do Carmo. Análise textual discursiva. Ijuí: Unijuí, 2011.

RODRIGUES, Ângela; ESTEVES, Manuela. A análise das necessidades na formação de professores. Portugal: Porto, 1993.

SCHÖN, Donald Alan. Educando o profissional reflexivo: um novo design para o ensino e aprendizagem. Tradução de Roberto Cataldo Costa. Porto Alegre: Artmed, 2000.

TARDIF, Maurice. Saberes docentes e formação profissional. Petrópolis: Vozes, 2002.

VYGOTSKY, Lev Semyonovich. Psicologia pedagógica. Porto Alegre: Artmed, 2003. Disponível em: <www.educacaopublica.rj.gov.br/biblioteca/comportamento/0072.htm>. Acesso em: 08 ago. 2012. 